\title{
LIMITAÇÕES NO CATIVEIRO QUANTO A PROMOÇÃO DE BEM- ESTAR EM PRIMATAS NA PERCEPÇÃO DO VISITANTE DO ZOOLOGICO DE CURITIBA
}

Natalia Aline Soares Artigas ${ }^{1}$

Marta Luciane Fischer ${ }^{2}$

Resumo: A continuidade dos zoológicos tem sido condicionada à promoção de intervenções conservacionistas e educativas. Contudo, a legitimidade desses espaços é apoiada na demanda da população por entretenimento e contato com a natureza, abstendo-se de uma avaliação crítica a respeito dos limites éticos envolvidos na relação com os animais. Objetivou-se caracterizar o entendimento do visitante quanto ao cativeiro de primatas e analisar a influência do público no comportamento dos animais. Constatou-se que os entrevistados identificaram as limitações do recinto e sugeriram mudanças para elevação do grau bem-estar animal. Porém, não relacionaram sua presença como fator de estresse. Os dados suportam a necessidade de ampliação de intervenção da Educação Ambiental aliada a um eficiente processo de comunicação aprimorado por meio da Bioética Ambiental.

Palavras-chave: Ética Animal; Bioética Ambiental; Educação Ambiental; Vulnerabilidade; Biofilia.

\footnotetext{
1 Pontifícia Universidade Católica do Paraná. E-mail: nasa.artigas@gmail.com.
}

2 Pontifícia Universidade Católica do Paraná. E-mail: marta.fischer@outlook.com. 


\section{Introdução}

Os zoológicos acompanharam o percurso da humanidade, sendo pioneiras as coleções de animais de antigos egípcios simbolizando poder e religião. A prática culminou na associação a uma finalidade científica, intensificando a visitação a esses espaços, inicialmente isenta de uma preocupação com o bem-estar animal (BEA) (YOUNG, 2003). A necessidade do ser humano em interagir com elementos naturais como meio de promoção do seu bem-estar biopsicossocial tem respaldo evolutivo apoiado na teoria da Biofilia (KELLERT; WILSON, 1995). Logo, é idôneo que a sociedade conclame por espaços de lazer, recreação e que tenha a oportunidade de interagir com os animais (FISCHER et al., 2017b). Legitimando, assim, a concepção tradicional dos zoológicos como locais de entretenimento e lazer, concomitante a possibilidades de interação com o inusitado e o contato com a natureza. Segundo McPhee e Carlstead (2010), nas áreas urbanas os zoológicos podem ser a única oportunidade de as pessoas conhecerem animais selvagens, cuja possibilidade de sensibilização dos visitantes está condicionada ao atendimento das suas necessidades e expectativas (ARAGÃO; KAZAMA, 2014a).

A promoção de condições de sobrevivência a animais cativos compõe o repertório de obrigações dos zoológicos, condicionados à exibição de comportamentos naturais e elevado grau de BEA (FISCHER et al., 2017b; LEIRA et al., 2017). A ciência do BEA visa conhecer, avaliar e garantir as condições para satisfação das necessidades físicas e mentais dos animais mantidos cativos sob a tutela do homem (RAMOS, 2006; NETO et al., 2011). Para tal, apoiam-se em indicadores de baixo grau BEA incluindo: a redução da expectativa de vida; supressão da reprodução; lesões corporais; doenças e comportamentos anormais (BROOM, 1991). Para garantir condições mínimas de BEA foram propostas as "cinco liberdades" referidas pioneiramente no relatório do Comitê Brambell em 1965, considerando que todo animal mantido cativo, independente do local e finalidade, deve estar livre: a) de fome e sede; b) de enfermidades; c) de medo e ansiedade; d) de instalações inadequadas; e) para expressar seus comportamentos naturais (FROEHLICH, 2015; PACHECO et al., 2012; ARAGÃO; KAZAMA, 2014b). A existência de comportamentos estereotipados tem sido amplamente utilizada como indicador de baixo grau de BEA, inclusive em primatas (SADE, 2013). Estes, são desencadeados pelo estresse resultante da privação da liberdade. A sobrecarga no sistema de controle igualmente reduz o sucesso reprodutivo, aumenta a mortalidade e compromete 0 crescimento e a capacidade imunológica favorecendo o surgimento de inúmeras enfermidades (SILVA et al., 2009; FISCHER et al., 2017b).

O enriquecimento ambiental tem sido utilizado como um meio de diminuir os impactos do ambiente estéril e artificial do cativeiro, que deve ser intrinsicamente relacionado a biologia, ecologia, comportamento e história natural do animal (YOUNG, 2003; NETO et al., 2011; FISCHER et al., 2016a, LEIRA et al., 2017). Existem cinco tipos de enriquecimento: a) social: promulga 
a interação com outros animais; b) cognitivo: estimula a realização de tarefas; c) físico: promove alterações no ambiente, aproximando-o do natural; d) sensorial: estimula respostas visuais, auditivas, olfativas, táteis e gustativas; e) alimentar: promove a manipulação do alimento estimulando forrageamento natural (FISCHER et al., 2016a; LEIRA et al., 2017).

A Educação Ambiental (EA) compõe o rol de atividades da maioria dos zoológicos, congregando atividades diversas que visam promover meios de despertar a consciência ecológica (COSTA, 2004). Segundo Mafaldo e Pinheiro (2011), a EA deve ser prioridade dos governos por meio da destinação de recursos. Assim como da sociedade civil por meio da atuação protagonista na manutenção da qualidade de vida no planeta por meio da modificação de seus hábitos e atitudes. Contudo Bosa e Sobota (2011) alertaram que precisa ser contínua para gerar frutos, além de demandar investigação para análise de qual a melhor maneira de utilização das ferramentas de comunicação, para que assim a EA atinja seus objetivos (LUMMERTZ; FISCHER, 2017). Inclusive a aplicação de ações educacionais deve ser avaliada para ser aproveitada em ambientes estratégicos, dessa forma, a ação será mais específica (FISCHER; TAMIOSO, 2016). Segundo Marino et al., (2010), muitas intervenções de EA realizadas em zoológicos e aquários foram mal conduzidas e ineficazes na mudança de atitudes dos visitantes, no qual o "efeito da novidade" promove uma experiência inusitada e emocionante, porém efêmera.

A análise da percepção, concepção e representação das pessoas pode e deve ser utilizada como norteadora das intervenções de EA em situações diversas como áreas de proteção ambiental, onde seu sucesso ainda pode potencializar uma gestão mais eficaz quando subsidiada por políticas públicas (FISCHER et al., 2017a), e também o uso de animais em ambientes educacionais (FISCHER; TAMIOSO, 2013), como consumo, serviço, entretenimento e companhia (FISCHER et al., 2016b; FISCHER et al., 2016c; FISCHER; TAMIOSO, 2016) e em exposição em zoológicos (FISCHER et al., 2017b). Segundo Aragão e Kazama (2014a), a percepção ambiental preconiza a tomada de consciência do ambiente pelo homem e a compreensão de que precisa proteger e cuidar, além de reconhecer opiniões diferentes e auxiliar na avaliação das necessidades e limitações. Os estudos de Fischer e Tamioso (2016) indicaram que estudantes universitários demonstram preocupação com os animais utilizados pelos seres humanos e que a ética deve ser tratada como foco nas intervenções de EA.

A Bioética tem como premissa que toda decisão humana que gere sofrimento e vulnerabilidade e vá contra a vida, em todas suas manifestações, é imoral e deve ser mitigada (FISCHER et al., 2016b). O papel da Bioética visa viabilizar o diálogo entre os agentes morais e equalizar as decisões baseadas em valores comuns (POTTER, 2016). Franco et al., (2014) frisaram a necessidade de equilíbrio entre as considerações emocionais atreladas ao campo da Ética e as racionais e objetivas, próprias da Ciência. Culminando em soluções responsáveis e viáveis, amparando os humanos, os animais e o ambiente. Embora a intenção original seja a conexão, a relação tem sido 
alicerçada nos valores da ética antropocêntrica, quando os indivíduos visam sua própria satisfação, eximindo-os da percepção das consequências do confinamento no BEA. Novos paradigmas quanto aos limites impostos na relação com os animais, tem inserido valores utilitaristas, sensiocêntricos e bem-estaristas cuja manutenção dos animais em cativeiro é considerada legítima, porém, condicionada a intervenções que elevem o grau de BEA (FISCHER; TAMIOSO, 2016). Porém, confrontando com visões abolicionistas (FRANCIONE, 2013; REGAN, 2006) que não aceitam a utilização dos animais para suprir quaisquer necessidades humanas, especialmente as voltadas ao entretenimento. Fischer et al., (2017b) atribuíram expectativa à habilidade da Bioética Ambiental no auxílio para resolução do dilema ético nos zoológicos, cuja complexidade permeia os interesses dos animais e dos seres humanos.

O Brasil é um dos países que congregam a maior diversidade de primatas neotropicais, com cerca de 15 dos gêneros apenas na Amazônia (OLIVEIRA et al., 2009), além do Cerrado, Pantanal, Caatinga e Campos sulinos (NETO et al., 2011). Segundo a União Internacional de Conservação da Natureza (IUCN 2012-2014) várias destas espécies estão ameaçadas. A manutenção desses animais em cativeiro compromete seu BEA devido as discrepâncias como ambiente natural e a esterilidade de estímulos potencializando o aparecimento de comportamentos estereotipados (ALMEIDA et al., 2008). Dentre os fatores estressantes destaca-se a presença do público (SOUZA, 2010), cuja concentração, proximidade, produção de barulho e insistência de interação (CATIBOG-SINHA, 2008) podem resultar em distúrbios comportamentais tais como agressão intergrupal e problemas alimentares. Sade (2013) frisou a relevância em analisar a influência do público, levando em consideração o BEA, abordagens educativas e a pesquisa. Fischer e Tamioso (2016) destacaram que estudantes universitários concebem os zoológicos como meio de promoção de recuperação, conservação e EA, servindo também como local de entretenimento. Porém pontuaram que deveriam cobrar taxa de entrada para melhorar a qualidade de vida dos animais. Ressalta-se que muitas instituições exibem ao público animais doentes, sendo os próprios visitantes uma das causas, especialmente em pequenos primatas (AGORAMOORTHY, 2004). Para Catibog-Sinha (2008) é possível mudar a percepção e conscientização do visitante partindo da iniciativa dos zoológicos em promover BEA por meio da melhora do recinto e manejo dos animais.

Considerando as pesquisas que atestam que o público do zoológico é constituído essencialmente por grupos familiares em busca de lazer e integração com a natureza (ARAGÃO; KAZAMA, 2014a; CATIBOG-SINHA, 2008; FISCHER et al., 2017b) e que mamíferos e pássaros são concebidos como as principais atrações (CATIBOG-SINHA, 2008), o presente estudo questiona se o público é capaz de identificar limitações no cativeiro quanto a promoção de BEA desses animais. Tem-se como hipótese que a associação do zoológico com ações de entretenimento e descontração dificulta o acesso do público às reais condições de vida dos animais, principalmente quando o recinto aparentemente demostra melhores condições e os animais são intrinsicamente ativos. Prejudicando, assim, a reflexão sobre as reais Revbea, São Paulo, V. 14, № 2: 49-68, 2019. 
necessidades de espaço e enriquecimento ambiental e principalmente sobre a influência da visitação no comportamento dos animais. Desta forma, objetivouse avaliar a opinião do visitante em relação ao ambiente de cativeiro de macacos-aranha da espécie Ateles paniscus (Linnaeus, 1758) mantidos no Zoológico Municipal de Curitiba e analisar o impacto da visitação no comportamento dos animais. Os resultados do presente estudo foram interpretados e refletidos norteados pela ideia central que a Bioética Ambiental pode ser inserida nesta questão ética complexa, plural e global na identificação e mitigação das vulnerabilidades. Consequentemente, associada com a EA deve-se investir no aprimoramento da comunicação e consequentemente promover valores comunitários visando a existência harmônica do homem com os elementos naturais. Assim como contribuir para construção do cidadão autônomo, crítico, consciente e protagonista em prol da sustentabilidade e da ética na relação do homem com a natureza e em especial com animais mantidos cativos para o seu entretenimento.

\section{Metodologia}

O estudo foi realizado no Zoológico Municipal de Curitiba, Paraná. Inaugurado em 1982, congrega uma área de $589 \mathrm{mil} \mathrm{m}^{2}$ situada no Parque Municipal do Iguaçu, com uma distância de cerca de 22,6 km do centro de Curitiba. Anualmente recebe cerca de 650 mil visitantes, sem a cobrança de taxa de entrada. O espaço configura entre um dos cinco zoológicos mais conceituados do Brasil e abriga em média 2.315 espécies. A instituição abarca o "Centro de Educação Ambiental" que atende o visitante com exposição de peças taxidermizadas, além de visitas orientadas e monitoradas com estudantes da rede pública e privada da região (PREFEITURA MUNICIPAL DE CURITIBA, 2017). O Zoológico conta com diversos programas de EA, como: visitas educativas, acantonamento ecológico, zooterapia, "o zoo vai à escola", "uma noite no museu", atividades destinadas a diversos tipos de públicos (BOSA et al., 2007).

Para testar a hipótese de predominância de valores utilitaristas na relação com animais mantidos cativos para entretenimento como resultado da dificuldade de identificação de fragilidades diante das emoções positivas decorrentes da presença do animal, foi selecionado um recinto que se destaca positivamente devido ao seu tamanho, localização e presença de elementos físicos na composição do ambiente. O recinto se constitui de uma ilha de cerca de 602,22 $\mathrm{m}^{2}$ contendo vegetação rasteira, arbustos, troncos finos sem galhos, cordas para distração dos animais, árvores baixas e dois abrigos para os primatas se refugiarem das condições adversas do tempo e do público (Figura $1 \mathrm{~A}$ e B).

A espécie Ateles paniscus, popularmente conhecida como macacoaranha (MA) é um animal de ambiente florestal, com membros e cauda longos que usa como um quinto membro, para se locomover pelas copas das árvores (CARVALHO; OTTA, 1998). Há registros da espécie nas florestas tropicais, na Floresta Nacional Saracá-Taquera, no Pará (Brasil), com grupos de até 18

revista brasileira 
indivíduos (OLIVEIRA et al., 2009). Devido ao cativeiro não conseguir suprir as demandas naturais, por ser uma espécie nativa e ativa a mesma foi escolhida para testar a hipótese de que as pessoas possuem dificuldades de identificar as limitações éticas envolvidas na manutenção de um animal cativo. Segundo o veterinário do zoológico Manoel Javorouski (comunicação pessoal), os dois macacos-aranha da testa branca, um macho e uma fêmea (Figura $1 \mathrm{C}$ e D), presentes na ilha foram incorporados ao zoológico em julho de 2000 quando ainda eram jovens, contudo sem idade definida.

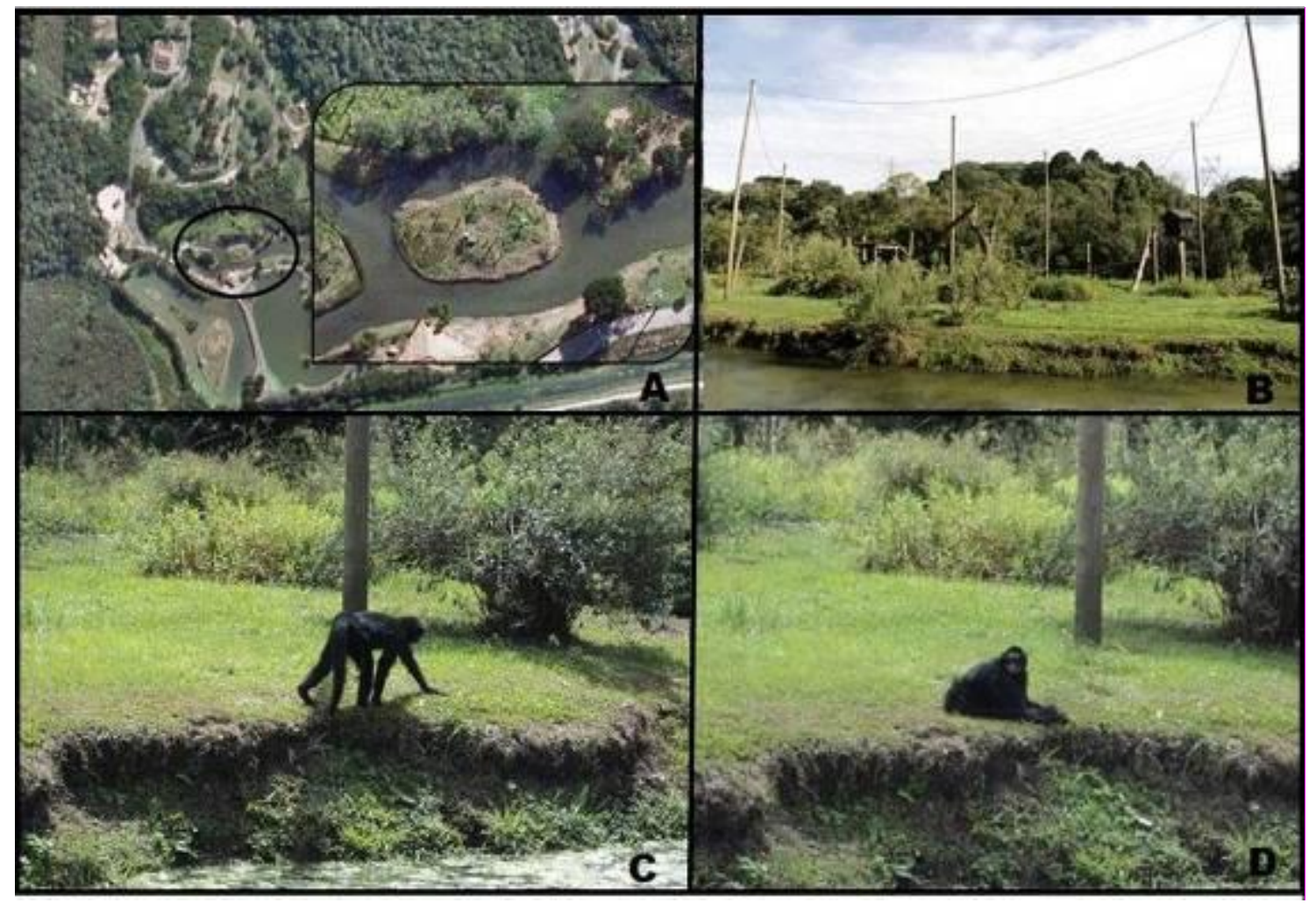

Figura 1. A: Imagem de satélite disponibilizada pelo Google Maps do Zoológico Municipal de Curitiba sendo delimitada em linha negra a área específica do recinto onde o estudo foi realizado. B: Foto da frente do recinto (ilha) dos macacos-aranha. C e D: Os dois macacosaranha presentes no Zoológico Municipal de Curitiba (do lado esquerdo a fêmea Nikita; do lado direito o macho Zulu). Fonte: Próprio autor.

\section{Técnicas e instrumentos para construção dos dados e análise}

O instrumento para acessar a opinião dos visitantes foi construído especificamente para a pesquisa baseando-se nas condições físicas do recinto. Mesmo a ilha sendo grande, quando comparada com outros recintos, ainda apresenta limitações, como um pequeno refúgio do público, sendo o mesmo espaço restrito para proteção das condições adversas do tempo, presença de poucos animais, árvores baixas e com pouco enriquecimento ambiental. Com base nessa observação e na teoria nas 5 liberdades, foram construídas 8 questões: 6 fechadas com atribuição à notas de 5 a 10; e 2 questões abertas em que os respondentes poderiam expor as opiniões pessoais quanto ao 
cativeiro. As questões de pontuação abordaram: a) condições de vida dos animais no zoológico; b) condições dos recintos em relação ao macaco-aranha; c) espaço para locomoção; d) abrigo das condições adversas do tempo; e) interação com animais de outras espécies; f) condições para se esconderem do público. As questões abertas consideraram se os visitantes observaram alguma atitude inadequada do público em relação aos macacos-aranha e possibilitava deixar sugestões para melhorar o recinto. $O$ objetivo foi verificar se na opinião dos visitantes os animais viviam bem, mesmo em cativeiro aparentemente adequado, porém, sem condições necessárias para o BEA. O trabalho foi aprovado pelo Comissão de Ética no Uso de Animais da PUCPR (403.358) e do Comitê de Ética de Pesquisa da PUCPR (n. 662).

Os visitantes do zoológico foram entrevistados nos finais de semana, no período da tarde, ao passarem em frente ao recinto do MA. Todos foram abordados aleatoriamente, com a condição que detivessem alguns minutos de observação ao recinto do animal. De um total de 57 pessoas abordadas, 42 aceitaram participar da pesquisa, cujo instrumento foi aplicado em maiores de 18 anos e após a explicação do trabalho e assinatura do Termo de Consentimento Livre e Esclarecido.

\section{Avaliação da influência da visitação no comportamento do macaco- aranha}

Concomitantemente a abordagem dos visitantes se avaliou a influência do público no comportamento dos macaco-aranha e verificou-se a eficiência do recinto na promoção do BEA. Devido à possibilidade de identificação individual dos animais, após a aplicação do método qualitativo ad libitum aplicou-se o método quantitativo animal focal (KAISER et al., 2011). No período entre dezembro de 2011 e março de 2012 foram realizadas 90 horas de observações diretas ao animal, divididas em três fases: a) 30 horas para montagem do etograma, utilizando o método ad libitum com registros em diferentes condições ambientais; b) 30 horas para quantificação sem a presença do público; c) 30 horas para quantificação com a presença do público, nos finais de semana. Todo o tempo despendido em atividades de manutenção, exploração e interações das categorias comportamentais foram registradas. As observações foram realizadas sempre se atentando ao fato de estar fora do alcance de visão do animal, assinalando os comportamentos no etograma, a fim de proceder registros instantâneos a cada cinco minutos.

A homogeneidade da amostra foi testada comparando os dados de média (questões do questionário de pontuar) por meio do teste Anova, enquanto que os dados categóricos (frequência de exibição de padrões motores relativos à alimentação, locomoção, exploração, descanso, interações sociais e comportamentos estereotipados) entre as variáveis (sem/com visitação; manhã/tarde; macho/fêmea) foram comparados por meio do teste do qui-quadrado. Considerou-se como hipótese nula a ocorrência de frequência 
homogênea das categorias comparadas, em uma confiança de $95 \%$ e a um erro de $5 \%$.

\section{Resultados}

\section{Percepção dos visitantes}

A análise da percepção dos visitantes indicou atribuição de valores diferentes para os quesitos avaliados, sendo que as maiores notas foram atribuídas a percepção de que o recinto promovia qualidade de vida aos animais (Figura 2). Contudo os respondentes indicaram a baixa expectativa de que o recinto efetivamente poderia promover proteção da condição climática, interações entre os animais e refúgio do público. A relação entre a qualidade do recinto para $o$ animal e como promotor de boa locomoção receberam avaliações intermediárias (Figura 2).

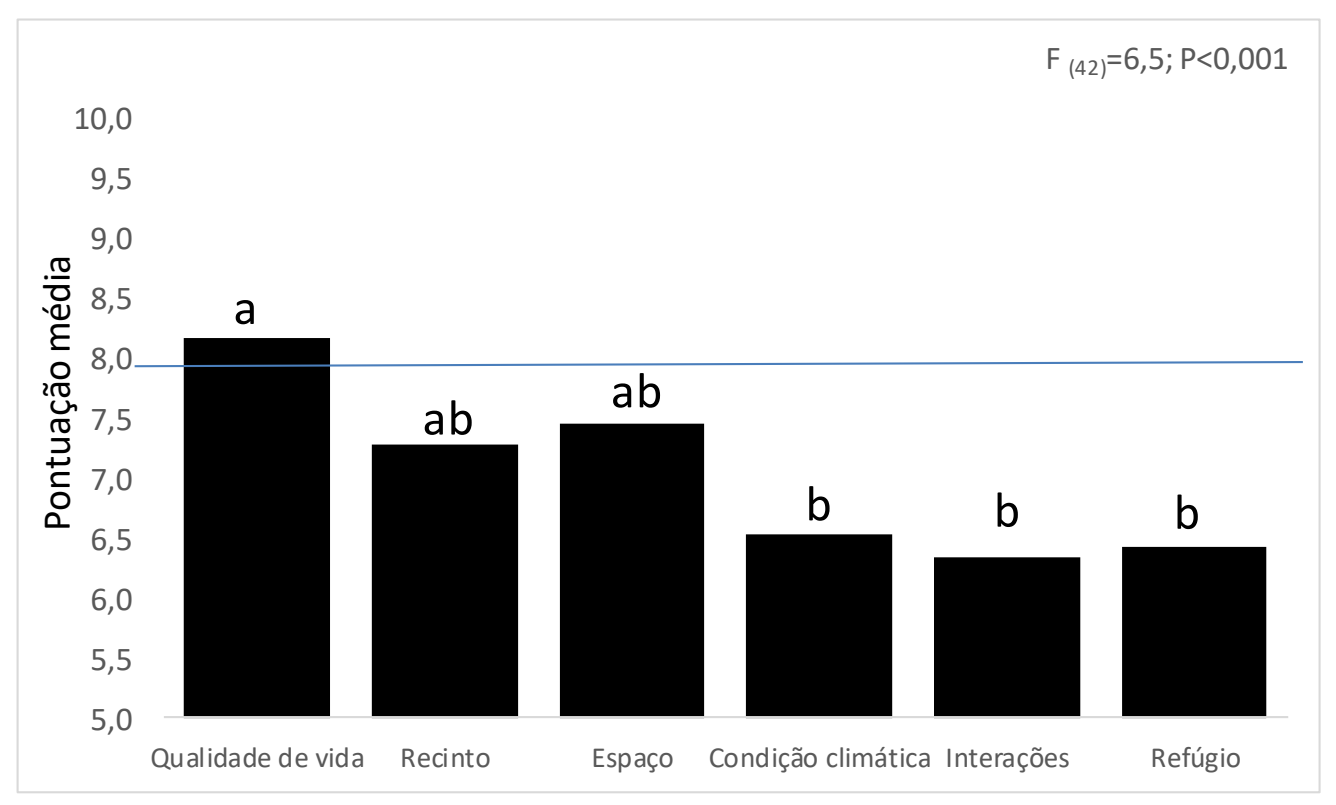

Figura 2. Pontuação média atribuída pelos visitantes do Zoológico Municipal de Curitiba, quanto ao recinto do macaco aranha, na promoção da qualidade de vida como um todo, na qualidade do recinto como todo, como espaço para locomoção, na proteção de intempéries, interações com outros animais e refúgio do público. A homogeneidade da amostra foi atestada pelo teste Anova, sendo os valores estaticamente diferentes $(P<0,05)$ representados por letras

\section{distintas. Fonte: dados da pesquisa.}

As respostas abertas também indicaram diferenças, sendo que $66,6 \%$ dos entrevistados não perceberam nenhuma atitude inadequada do público com relação aos animais. Os outros $33,3 \%$ perceberam atitudes como: jogar alimento nos animais, atirar objetos ou pedras, gritar para chamar a atenção do animal e ultrapassar a grade de proteção. A última questão indicou que 7,1\% dos entrevistados acreditam que não é necessário melhorar o recinto dos macacos-aranha, enquanto que $92,9 \%$ responderam que é possível melhorar o Revbea, São Paulo, V. 14, № 2: 49-68, 2019. 
recinto, indicando sugestões como aumentar o espaço $(42,8 \%)$ e arborizar o local para obtenção de sombra $(28,6 \%)$, abrigos novos e melhores $(19 \%)$, inserir mais indivíduos no recinto $(11,9 \%)$, uma gama maior de brinquedos ou cordas para distração $(11,9 \%)$, entre outras propostas menos frequentes, como, isolar o ambiente e ter mais proteção para os animais (9,5\%), um abrigo melhor $(7,1 \%)$, mais animais no zoológico e uma limpeza mais adequada $(4,7 \%$ cada) e trocar os animais de recinto $(2,3 \%)$.

\section{Quantificação dos padrões motores}

Os atos comportamentais dos animais registrados foram agrupados em sete categorias comportamentais conforme Kaiser et al., (2011): alimentação, locomoção, exploração, descanso, interações sociais, comportamentos estereotipados, sendo os mais frequentes: exploração (28\%), descanso (27\%) e locomoção $(25 \%)\left(\chi^{2}(6)=2040 ; \mathrm{P}<0,001\right)$ (Figura 3).

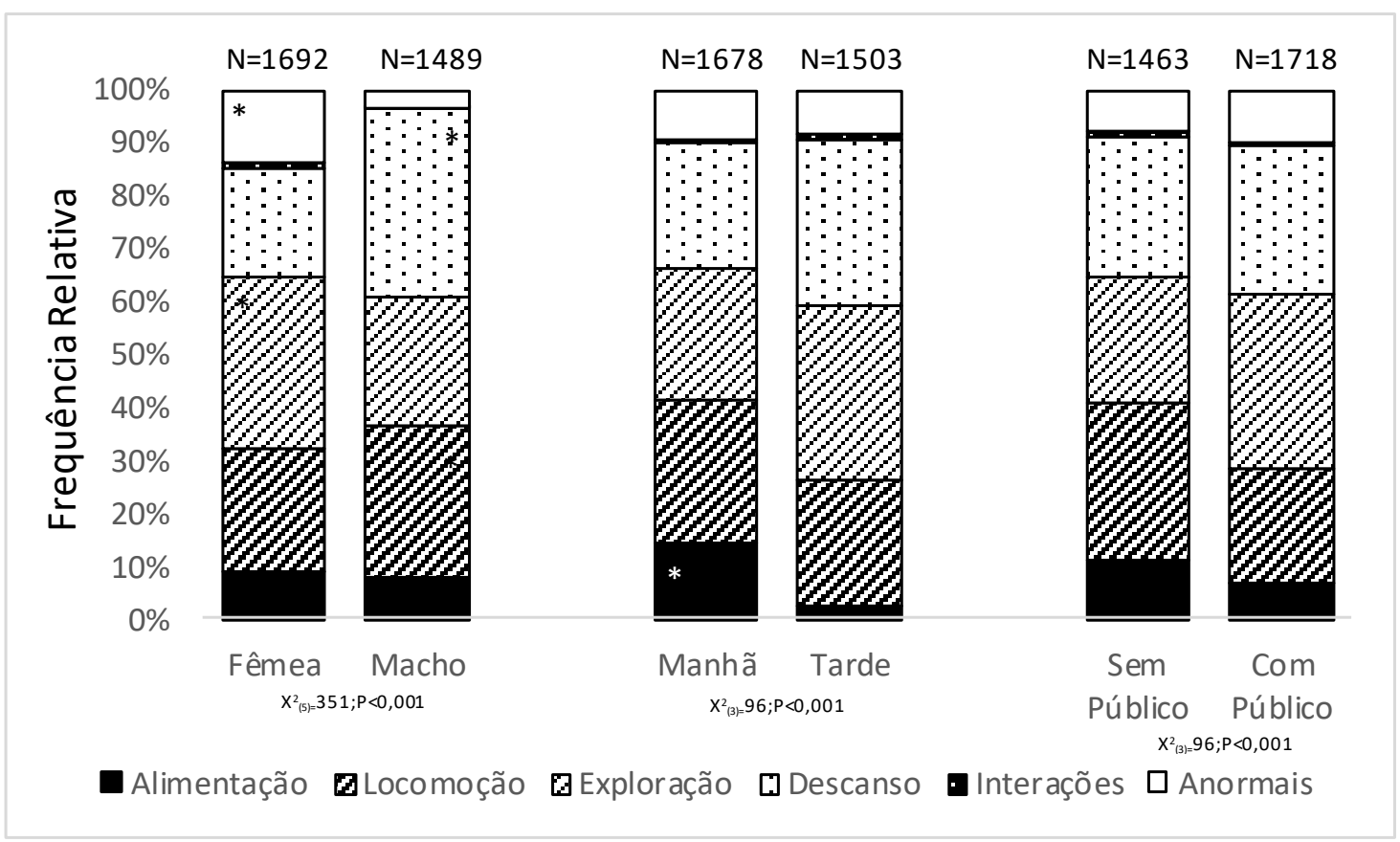

Figura 3. Frequência das categorias comportamentais dos macaco-aranha do Zoológico Municipal de Curitiba, comparativamente entre fêmea/macho, manhã/tarde e sem/com público. A homogeneidade dos dados foi acessada por meio do teste do qui-quadrado, sendo os valores significativamente maiores $(\mathrm{P}<0,05)$ acompanhados de asterisco $\left({ }^{*}\right)$.

Fonte: dados da pesquisa.

$\mathrm{Na}$ alimentação pronunciaram-se dez atos comportamentais prevalecendo "esperando a alimentação" (57\%) e "sentado comendo a alimentação utilizando uma pata" $(27 \%)\left(\chi^{2}(4)=309 ; P<0,001\right)$. A locomoção foi representada por oito padrões motores, destacando-se "andando" $(55 \%)$ e 
"subindo e descendo do poste" $(8,9 \%)\left(\chi^{2}(8)=1570 ; P<0,001\right)$, enquanto que na categoria exploração (com dezenove condutas), pronunciaram "sentado observando o ambiente" (51\%) e "sentado observando o público" (35\%) $\left(\chi^{2}(9)=2631 ; P<0,001\right)$. As interações sociais com 12 atos comportamentais foi caracterizada principalmente pelas condutas "sentado, brincando com outro primata" (36\%) e "parado observando ou interagindo com o público" (22\%) $\left(\chi^{2}(4)=4 ; \mathrm{P}<0,001\right)$. Na categoria descanso, onde foram categorizados onze comportamentos, predominaram "deitado descansando" (34\%) e "sentado na sombra" $(28 \%)\left(\chi^{2}(6)=752 P<0,001\right)$. Os comportamentos estereotipados foram caracterizados por doze condutas (sentado, se coçando; deitado, se coçando; andando, se coçando; sentado, beliscando; deitado, beliscando; andando, beliscando; sentado, mordendo a si mesmo; deitado, mordendo a si mesmo; andando, mordendo a si mesmo; dando cambalhotas; subir e descer dos postes; e deslocamento contínuo entre galhos ou no solo), destacando-se "sentado se coçando" $(76 \%)$ e "cambalhotas" $(10 \%)\left(\chi^{2}(5)=738 ; P<0,001\right)$.

O macho diferiu da fêmea na expressão do seu comportamento $\left(\chi^{2}(6)=351 ; \mathrm{P}<0,001\right)$, sendo o descanso $(35 \%)$ e a locomoção $(28 \%)$ mais frequentes no Zulu e a exploração (32\%) e os comportamentos estereotipados (13\%) na Nikita. O período diário também influenciou na expressão do comportamento $\left(\chi^{2}(6)=277 ; \mathrm{P}<0,001\right)$, sendo pela manhã mais frequentes a locomoção (26\%); a alimentação (14\%) e os comportamentos estereotipados $(9,6 \%)$ (Figura 3) e a tarde, a exploração (32\%) e o descanso (31\%).

A presença do público influenciou significativamente na expressão dos comportamentos exibidos pelos MA $\left(\chi^{2}(6)=143 ; P<0,001\right)$, atestando-se que a exploração (32\%); o descanso (28\%); e os comportamentos estereotipados $(9,8 \%)$, foram mais frequentes na presença do público, enquanto que a locomoção (21\%) e a alimentação (6,6\%) na ausência do público (Figura 3).

\section{Discussão}

O presente estudo evidenciou que os visitantes do Zoológico de Curitiba foram capazes de perceber as condições de BEA dos macacos cativos ao serem conduzidos a observar quesitos específicos. Porém, contrapondo com a primeira impressão na qual mostraram não se atentarem aos impactos do cativeiro no animal, principalmente quanto a influência do público, provavelmente motivados pelo prazer momentâneo desencadeado pelo entretenimento, novidade e lazer.

O fato de os respondentes terem atribuído notas altas para avaliações gerais a respeito da adequação do recinto e notas baixas para as específicas sugere o predomínio de condicionantes emocionais aos racionais na reflexão sobre a realidade vivenciada. A população geralmente não detém parâmetros para avaliar se um animal mantido no zoológico está bem ou não. Segundo Clayton et al., (2008), há o estabelecimento de uma relação de confiança do cidadão na Instituição e crença de que há preocupação em manter os animais 
saudáveis, sobretudo pelo interesse de atração dos visitantes. Os mesmos autores atestaram diferenças de aceitação da EA pelos visitantes, sendo que as pessoas que buscam o zoológico para aprender sobre os animais normalmente estão interessadas em seu modo de vida, diferente daquelas que o visitam apenas para diversão. Logo, espera-se que pessoas mais envolvidas com questões éticas, como os estudantes chineses analisados por Davey (2006) e universitários entrevistados por Fischer e Tamioso (2016), rejeitem o tratamento tradicional direcionado aos animais cativos, conclamando por atitudes éticas, eximindo-os de sofrimento. Aragão e Kazama (2014b) identificaram que a maioria dos seus entrevistados acreditava que os zoológicos são importantes para os animais devido a capacidade de estratégias de conservação. Isso demonstra que as pessoas visitam os parques atribuindo-Ihes importância e esperando condutas responsáveis do estabelecimento, porém, evidenciando que é possível implementar a EA através de animais cativos quando se é especificado o modo de vida que os mesmos deveriam apresentar.

As respostas espontâneas revelaram que o público é capaz de inferir no que pode ser melhorado contribuindo com sugestões, requerendo que o comportamento natural seja evidente e compatível com aquelas que compõem a pauta do enriquecimento ambiental. $O$ fato de perceberem espontaneamente que no recinto demanda por estrutura, mais árvores, brinquedos e mais indivíduos da espécie, elucidam que a percepção de condições mínimas para o BEA não necessita de um conhecimento técnico, mas de uma percepção das necessidades da espécie. Clayton et al., (2008) atestaram em relatos de visitas ao zoológico a associação da experiência vivida com sensações de relaxamento e felicidade, destacando o aprendizado ao ser estimulada a curiosidade e o interesse em conhecê-los. Logo, como atestado na presente pesquisa, Mcphee e Carlstead (2010) apontaram que os visitantes preferem observar um ambiente mais próximo ao natural. Os autores indicaram que podem identificar infelicidade em animais que exibem comportamentos repetitivos, o que desencadeia a reflexão sobre a importância biológica daqueles animais e da necessidade de sua conservação. Essa preferência para Fernandez et al., (2009) está atrelada a maior atividade dos animais e, consequentemente, a maior exposição para o público, correspondendo às expectativas de Clayton et al., (2008) de que a observação do comportamento do animal estimula o aprendizado, legitimando a função de conservação atribuída aos zoológicos. Logo segundo McPhee e Carlstead (2010), é responsabilidade das Instituições promover comportamentos naturais em animais cativos com programas que acarretem em elevação do grau de BEA. Para tal, Agoramoorthy (2004) alertou da necessidade de investimentos holísticos para a conservação e BEA, com justiça e equidade, principalmente a fim de reavaliar e aumentar a conscientização do cidadão. Segundo Broom e Molento (2004) é desejável que as pessoas sejam informadas a respeito da importância do BEA e em quais áreas se encontram os problemas e principalmente qual a sua parcela de responsabilidade direta e indireta. Assim, se faz necessária a implantação de ambientes mais próximos aos naturais, 
permitindo que o visitante saia do zoológico com a imagem de um animal saudável em meio a sua natureza, uma vez que a medida que os visitantes percebem que o animal apresenta boas condições de vida e que seu BEA está elevado, ele aprende mais e se interessa pela vida do animal.

O visitante do zoológico não se absteve de exibir comportamentos inadequados diante do recinto, mesmo reconhecendo as limitações impostas aos animais como atestado por Aragão e Kazama (2014b). Almeida (2008) atribuiu essa conduta a intenção primária de diversão levando-o inclusive a ignorar as informações sobre os animais dispostas em cartazes, principalmente referente a não alimentação e dos riscos que esse ato pode trazer para a saúde do animal (Leira et al., 2017). Fato igualmente registrado no presente estudo e conclamado com reforço por Vaz e Carvalho (2010). Para Fernandez et al. (2009) a inatividade do animal pode ser um condicionante da impressão negativa do público levando a condutas prejudiciais ao BEA. Portanto, diante da baixa adesão dos visitantes aos informativos Clayton et al. (2008) reforçaram a necessidade de aprimoramento das atividades educativas. Segundo Dorigo e Ferreira (2015), devido a percepção ser um processo individual influenciado por padrões culturais e sociais, é fundamental o diagnóstico da aspiração de cada público a fim de prover ações efetivas de conscientização. Ainda ressaltaram que a população passa a refletir quando ações palpáveis lhes são aplicadas e podem acarretar no questionamento de atitudes voltadas ao ambiente com práticas sustentáveis. Sendo assim, se faz necessária a disponibilização de cartazes/placas informativos ressaltando comportamentos dos animais, vistos como divertimento, mas que são indicativos de baixo BEA e até mesmo as mais clássicas, como: evite jogar alimento para os animais, procure fazer silêncio próximo aos recintos. $O$ zoológico não deve se limitar em informar e sim incentivar ações práticas.

O comportamento dos primatas avaliados neste estudo foi influenciado tanto pelo período do dia quanto pela presença do público. A influência do período diário se deu principalmente em decorrência do estresse pré-alimentar, uma vez que o animal condicionado a se alimentar sempre no mesmo horário, desenvolve a expectativa que antecede 0 oferecimento de alimento. Consequentemente, exibe atos comportamentais estereotipados, tais como registrados para a mesma espécie por Almeida et al. (2008), os quais relacionaram esse transtorno $\mathrm{com}$ a estreita relação das condutas que comprometem o atendimento eficaz das cinco liberdades (PACHECO et al., 2012). O condicionamento alimentar pode ser amenizado com o emprego de técnicas de enriquecimento ambiental alimentar.

A ocorrência de comportamentos diferenciais nos macacos frente às variáveis testadas, bem como a ocorrência de padrões motores estereotipados principalmente na presença de visitantes são indicativos do comprometimento do BEA. A alta frequência de atos comportamentais estereotipados, especialmente exibidos pela fêmea, na presença de visitantes, soma-se aos registros de ocorrência de padrões motores auto direcionados como coçar registrados em Alouatta sp. (SOUZA, 2010), de girar em torno do recinto em 
macacos-prego (RODRIGUES et al., 2010), alteração da ecologia de macacosprego (VAZ; CARVALHO, 2010), influência negativa na reprodução de Callithrix jacchus (SOUZA, 2010), aumento de agressividade e diminuição de comportamento social decorrente do barulho excessivo em cabras e ovelhas (ANDERSON et al., 2002) e em primatas no geral (FERNANDEZ et al., 2009). Souza (2010) e Rodrigues et al., (2010) apontaram o uso dessas respostas como indicadores de estresse e ansiedade e baixo grau de BEA, sendo que categoricamente Fernandez et al., (2009) associam a presença do público como prejudicial aos animais cativos. Assim, o fato do público se constituir de um forte condicionante de estresse em animais cativos, devido principalmente ao seu comportamento que na maioria das vezes é prejudicial ao animal, pode ser mitigado tanto com o enriquecimento ambiental quanto com a diminuição da exposição.

Embora o Zoológico de Curitiba já esteja se mobilizando na promoção do enriquecimento ambiental (ALMEIDA et al., 2008; FISCHER et al., 2017b), técnicas de enriquecimento sensorial, cognitivo e físico, como brincadeiras e atividades de manipulação do ambiente que estimulem os sentidos dos animais são necessárias para a diminuição de atos comportamentais estereotipados e a promoção efetiva das cinco liberdades (SOUZA, 2010) e do BEA (BROOM; MOLENTO, 2004). Para Aragão e Kazama (2014b) o recinto não deve ser apenas grande, mas proporcionar interatividade para os animais, com distrações para expressão do comportamento natural. Essa preocupação deve ser especialmente direciona para primatas devido sua intrínseca curiosidade e hábito explorador, somada a origem de ambientes florestais e modo de vida em grupos sociais (ALMEIDA et al., 2008). Assim, mesmo diante da constatação de Campos et al., (2005) que os cativeiros inadequados impõem aos animais selvagens condições muito diferentes das encontradas em seu ambiente natural, deve-se proporcionar um microambiente rico e diversificado (SOUZA, 2010). Ao disponibilizar condições naturais de vida aos animais, não apenas alimentares, mas qualquer forma de enriquecimento ambiental, os mesmos poderão apresentar comportamentos exploratórios, o que pode converter em aumento do grau de BEA (KAISER et al., 2011; LEIRA et al., 2017). A diminuição dos efeitos do público para Fernandez et al., (2009) pode ser alcançada com a interposição de uma rede de camuflagem entre os visitantes e os animais, potencialmente como promotor de exibição de comportamentos mais naturais reforçando a aplicação de enriquecimento como meio de angariar esforços para a conservação. Aragão e Kazama (2014b) pontuaram que os visitantes de zoológicos almejam que o recinto dos animais seja mais parecido com o ambiente natural, além de ser limpo, grande e interativo, intensificando seu BEA. Acredita-se que quando os animais passam a apresentar comportamentos mais exploratórios e típicos da espécie na presença dos visitantes, os mesmos têm uma vivência real da situação de enriquecimento ambiental e BEA e tomam conhecimento de seu comportamento anormal, instigando-os a se posicionarem de acordo com valores éticos biocêntricos.

O fato de os entrevistados não terem levantado a questão da influência negativa do público contrapondo com as evidências contrárias indica 
urgentemente a necessidade de intervenção educativa. No Sudeste Asiático a Associação de Zoológicos constituiu um Comitê de ética e BEA que objetiva monitorar a situação técnica e ética envolvidas com animais cativos, além de propor soluções para mitigar e prevenir essas questões (AGORAMOORTHY, 2004). Ações de tal magnitude, como de EA balizadas por princípios da Bioética Ambiental são essenciais para que se desenvolva a consciência ambiental e transpasse os limites físicos dos zoológicos substituindo valores antropocêntricos/utilitaristas por valores biocêntricos/ecocêntricos e inclusivos dos animais não humanos na comunidade moral. Por conseguinte, Aragão e Kazama (2014b) ressaltaram que a aplicação da EA precisa ser didática e acessível, abordando temas variados que vão desde a caracterização dos animais até a conduta dos visitantes, visando a conservação da fauna globalmente. Segundo Clayton et al., (2008) pessoas que aderem a esses novos paradigmas éticos são mais propensas a ajudarem os animais confinados, seja monetariamente ou pela multiplicação dos valores aprendidos. Segundo Bosa e Sobota (2011) a aplicação da EA, principalmente no ambiente escolar, acarreta na diminuição de problemas ambientais, inclusive quando passada de forma divertida aos ouvintes. Logo se faz necessário investimento na comunicação da EA em parques naturais, com palestras interativas e cursos de EA mais aprimorados, sendo que todas devem ser aplicadas de forma variada, conforme o grupo em questão e principalmente de forma lúdica. Visitas direcionadas e acompanhadas por monitores também são importantes para melhorar o conhecimento da população em relação aos animais que vivem em cativeiro, especialmente quando são identificadas e mitigadas as vulnerabilidades dos visitantes desses ambientes, pensando também no respeito com os animais e a natureza. Zoológicos internacionais já apresentam recintos mais realistas e associados à cada espécie e seu hábitat. Embora a ilha dos macacos-aranha estudados seja grande quando comparada com os demais recintos, ainda demanda por melhorias afim de mitigar os padrões motores estereotipados, subsidiando a necessidade de colocação de dispositivos e árvores no recinto para a sua distração, além da necessidade de enriquecimento físico no ambiente. Recomendações estas que foram feitas pelos próprios participantes da pesquisa, mostrando que a população está preparada para promover o BEA e levar essa prática adiante para a comunidade, fazendo com que outras pessoas percebam a necessidade de melhoras, sendo assim, constata-se a existência de conflitos éticos dentro do zoológico. Destarte, a bioética necessita interferir nesses espaços em que homem e natureza vivem juntos, com o diálogo o homem passa a respeitar outras formas de vida, pensando em suas ações e não colocando sua necessidade altruísta em primeiro lugar, dessa forma o respeito moral para com os animais será colocado em prática e desenvolvido dentro e fora dos zoológicos, fazendo com que a população viva a biofilia e eleve seu bem-estar biopsicossocial. 


\section{Considerações Finais}

O presente estudo atestou as hipóteses de o público ser capaz de perceber as condições dos animais cativos apenas quando são direcionados a refletirem sobre questões específicas. De uma forma geral consideram que os animais estão vivendo bem e confiam na idoneidade da instituição, balizados por reações emocionais positivas proporcionadas pelo entretenimento, lazer e inovações próprios dos zoológicos, assim, abstendo-se da concepção de que os mesmos detêm também a função de conservação e educação. Também foi confirmada a hipótese de atribuição de melhores condições devido ao recinto diferencial e ao hábito ativo desses macacos, inviabilizando a relação com evidências óbvias de que os primatas são naturalmente arborícolas de florestas densas e vivem em grandes grupos, condições inexistentes no recinto que poderiam ser amenizadas com o enriquecimento ambiental. As sugestões são importantes para melhorar a condição de vida e BEA dos MA, não apenas no cativeiro, mas também adaptar para outras espécies confinadas, sendo possível perceber que o zoológico estudado não está adaptado como outras instituições brasileiras que empregam recintos com condições ambientais semelhantes à dos animais na natureza. Ou até mesmo utilizam métodos alternativos para o entretenimento animal, como holografias e parques temáticos que utilizam um modelo animal em estátua ou taxidermizado como amostra real e palpável aos visitantes (FISCHER et al., 2017b).

As maiores evidências comportamentais do baixo grau de BEA foram os comportamentos estereotipados e a atividade dos animais na presença de visitantes no zoológico, fato que extrapola a responsabilidade na manutenção das condições de vida da instituição para os visitantes. Essas demandas já têm sido solucionadas por grandes empreendimentos que usam vidros antirruído, antiodores e unilateral em visão. Estas permitem que os animais sejam observados no seu dia a dia, apresentando comportamentos mais próximos aos naturais da espécie, contudo eles não entram em contado com as pessoas e incentivam pesquisas (FISCHER et al., 2017b), mas que demandam atitudes primárias como evitar barulho, estimulação e desrespeito com os animais.

$\mathrm{Na}$ atualidade a permanência ou extinção dos zoológicos tem composto a pauta de discussão de utilitaristas e abolicionistas, sendo classificados como problemas éticos, plurais e globais demandando a intermediação de normativas legais e bioéticas no desencadeamento de uma solução, compondo a agenda da bioética ambiental (LEIRA et al., 2017; FISCHER et al., 2017b). Em países, como Índia, Taiwan, Filipinas e Cingapura, já foram determinadas leis que visam o BEA, penalizando a crueldade com os mesmos, visando qualquer tipo de maus-tratos, essas leis deveriam servir de exemplo para vários outros países determinando assim o comprometimento ético (DAVEY, 2006).

O diálogo com a Bioética Ambiental se faz necessário nas pautas de BEA intrinsicamente atrelada com bem-estar da população. Logo, a associação dos zoológicos e Comitês Multidisciplinares de Bioética Ambiental, poderiam identificar e mitigar vulnerabilidades e promover um canal de comunicação mais efetivo com a população visando a mudança de comportamento do 
público, para que assim, seres humanos e animais vivam em harmonia, com comprometimento ético para si e outras formas de vida, construindo um público mais autônomo, crítico e consciente. Além disso, é importante considerar que a EA é essencial para a formação de uma consciência ecológica. Chama-se a atenção também para a necessidade de placas interativas nos recintos identificando a natureza daquele animal, seu hábitat e nicho ecológico, mostrando que não devem ser ofertados alimentos e priorizando o respeito a eles. Contudo, deve-se chamar a atenção do público, com práticas mais lúdicas e atraentes, principalmente aqueles visitantes de rotina, como grupos de escolas e famílias, ou seja, a população mais evidente nesses ambientes. Intervenções de EA em zoológicos são fundamentais e auxiliam no aprendizado, tanto das crianças como nos adultos, além de monitores que podem caminhar pelo parque auxiliando e ensinando à todos. A inclusão de ações bioéticas diretamente relacionadas com ações ambientais faz com que todos sejam beneficiados, os animais, a população e o próprio zoológico.

\section{Agradecimentos}

Aos profissionais do zoológico por liberar as observações, principalmente ao veterinário Manoel Javorouski pelas informações dos animais. $E$ aos participantes da pesquisa por disponibilizar seu tempo para responder os questionários.

\section{Referências}

AGORAMOORTHY, G. Ethics and welfare in Southeast Asian Zoos. Journal of applied animal welfare science. v. 7, n. 3, p. 189-195. 2004.

ALMEIDA, A. Como se posicionam os professores perante a existência e utilização de jardins zoológicos e parques afins. Educação e pesquisa. São Paulo, v. 34, n. 2, p. 327-342. 2008.

ALMEIDA, A.M.R.; MARGARIDO, T.C.C.; FILHO, E.L.A.M. Influência do enriquecimento ambiental no comportamento dos primatas do gênero Ateles em cativeiro. Arquivos de Ciências Veterinárias e Zoologia da Unipar. Umuarama, v. 11, n. 2, p. 97-102. 2008.

ANDERSON, U.S.; BENNE, M.; BLOOMSMITH, M.A.; MAPLE, T.L. Retreat space and human visitor density moderate undesirable behavior in Petting Zoo animals. Journal of applied animal welfare science. v. 5, n. 2, p. 125-137. 2002.

ARAGÃO, G.M.O.; KAZAMA, R. Percepção ambiental de visitantes do zoo de Brasília e a possibilidade de se aprender e ensinar nesse ambiente. Acta Scientiarum. Human and Social Sciences. Maringá, v. 36, n. 1, p. 63-71, jan./jun. 2014a. 
ARAGÃO, G.M.O.; KAZAMA, R. Percepção sobre o bem-estar de animais silvestres no zoológico de Brasília como ferramenta para educação ambiental. Revista de Educação ambiental. Rio Grande, v. 19, n. 2, p. 33-50. 2014b.

BOSA, C.R.; FRANCO, J.R.S.; SILVA, M.E.T.; MORAES, S.R.M. Educação ambiental: caminhos para mudar. Revista Acadêmica: Ciência Animal. v. 5, n. 4. 2007.

BOSA, C.R.; SOBOTA, A. Educação ambiental no acantonamento ecológico, Curitiba, Paraná. Monografias Ambientais. v. 2, n. 2, p. 216-227. 2011.

BROOM, D.M. Animal welfare: concepts and measurement. Journal of animal science. Reino Unido, v. 69, p. 4167-4175. 1991.

BROOM, D.M.; MOLENTO, C.F.M. Bem-estar animal: conceito e questões relacionadas - revisão. Archives of Veterinary Science. v. 9, n. 2, p. 1-11. 2004.

CAMPOS, B.; QUEIROZ V.S.; MORATO R.G.; GENARO, G. Padrão de atividades de onças pintadas (Panthera onca LINNAEUS, 1758) mantidas em cativeiro - manejo e comportamento. Revista de Etologia. v.7, n. 2, p. 75-77. 2005.

CATIBOG-SINHA, C. Zoo tourism: biodiversity conservation through tourism. Journal of ecotourism. v. 7, n. 2\&3. 2008.

CARVALHO, L.B.C.; OTTA, E. Interação mãe-filhote em macacos-aranha (Ateles paniscus). Interação em Psicologia. v. 2, n. 1. 1998.

CLAYTON, S.; FRASER, J.; SAUNDERS, C.D. Zoo experiences: conversations, connections, and concern for animals. Zoo biology. v. 28, n. 5, p. 377-397. 2008.

COSTA, O.G. Educação ambiental - experiências dos zoológicos brasileiros. REMEA-Revista Eletrônica do Mestrado em Educação Ambiental. v.13. 2004.

DAVEY, G. Chinese university student's attitudes toward the ethical treatment and welfare of animals. Journal of applied animal welfare science. Philadelphia, v. 9, n. 4, p. 289-297. 2006.

DORIGO, T.A.; FERREIRA, A.P.N.L. Contribuições da percepção ambiental de frequentadores sobre praças e parques no Brasil (2009-2013): revisão bibliográfica. Revista de gestão ambiental e sustentabilidade - GeAS. v. 4, n. 3, p. 31-45. set./dez. 2015.

FERNANDEZ, E.J.; TAMBORSKI, M.A.; PICKENS, S.R.; TIMBERLAKE, W. Animal-visitor interactions in the modern zoo: conflicts and interventions. Applied animal behaviour science. v. 120, n. 1, p. 1-8. 2009.

FISCHER, M.L.; AGUERO, W.P.; RODRIGUES, G.S.; SIMÃO-SILVA, D.P.; MOSER, A. M. Enriquecimento ambiental como princípio ético nas pesquisas com animais. Revista de bioética. v. 24, n. 3, p. 532-541. 2016a. 
FISCHER, M.L.; CORDEIRO, A.L.; LIBRELATO, R.F. A abstinência voluntária do consumo de carne pode ser compreendida como um princípio ético?. Ciências sociais unisinos. São Leopoldo, v. 52, n. 1, p. 122-131, jan./abr. 2016b.

FISCHER, M.L.; LIBRELATO, R.F.; CORDEIRO, A.L.; ADAMI, E.R. A percepção da dor como parâmetro de status moral em animais não humanos. Revista conexão ciência. v. 11, n. 2, p. 31-41. 2016c.

FISCHER, M.L.; PAROLIN, L.C.; VIEIRA, T.B.; GABARDO, F.R.A. Bioética ambiental e educação ambiental: levantando a reflexão a partir da percepção. Revista Brasileira de educação ambiental. São Paulo, v. 12, n. 1, p. 58-84. 2017 a.

FISCHER, M.L.; PROHNII, S.S.; ARTIGAS, N.A.S.; SILVERIO, R.A. Os zoológicos sob a perspectiva da bioética ambiental: uma análise a partir do estudo de caso dos felídeos cativos. Revista Iberoamericana de Bioética. v. 4, p. 1-17. 2017b.

FISCHER, M.L.; TAMIOSO, P.R. Bioética Ambiental: concepção de estudantes universitários sobre o uso de animais para consumo, trabalho, entretenimento e companhia. Ciências \& Educação. v. 22, n. 1, p. 163-182. 2016.

FISCHER, M.L.; TAMIOSO, P.R. Perception and position of animals used in education and experimentation by students and teachers of different academic fields. Estudos de biologia, ambiente e diversidade. v. 35 , n. 84, p. 85-98. jan./jun. 2013.

FRANCIONE, G.L. Introdução aos direitos dos animais: seu filho ou cachorro. Campinas: Unicamp, 2013.

FRANCO, A.L.; NOGUEIRA, M.N.M.; SOUSA, N.G.K.; FROTA, M.F., M.; FERNANDES, C.M.S.; SERRA, M.C. Pesquisas em animais: uma reflexão bioética. Acta Bioethica. v. 20, n. 2, p. 247-253. 2014.

FROEHLICH, G. Entre índices e sentimentos: notas sobre a ciência do bemestar animal. Revista Florestan, v. 02, n. 4, p. 73-83, dez. 2015.

KAISER, S.K.; MARGARIDO, T.C.C.; FISCHER, M.L. Avaliação do comportamento de cutias Dasyprocta azarae e Dasyprocta leporina (Rodentia: Dasyproctidae) em cativeiro e semicativeiro em parques urbanos de Curitiba, Paraná, Brasil. Revista de etologia. v. 10, n. 2, p. 68-82. 2011.

LEIRA, M.H.; REGHIM, L.S.; CUNHA, L.T.; ORTIZ, L.S.; PAIVA, C.O.; BOTELHO, H.A.; CIACCI, L.S.; BRAZ, M.S.; DIAS, N.P. Bem-estar dos animais nos zoológicos e a bioética ambiental. PUBVET, v.11, n.7, p. 545-553, 2017.

KELLERT, S.R.; WILSON, E.O. (Ed.). The biophilia hypothesis. Island Press, 1995.

LUMMERTZ, T.B.; FISCHER, M.L. O teatro como ferramenta de promoção de educação ambiental. Revista Brasileira de educação ambiental. São Paulo, v. 12, n. 5, p. 56-72. 2017. 
MAFALDO, M.F.G.; PINHEIRO, D.K. Ensinando técnicas de reciclagem, reutilização e redução dos resíduos sólidos urbanos para alunos do $4^{\circ}$ ano do ensino fundamental da EEEF Eduardo Vargas em Alegrete/RS. Monografias Ambientais. v. 3, n. 3, p. 349-361. 2011.

MARINO, L.; LILIENFELD, S.O.; MALAMUD, R.; NOBIS, N.; BROGLIO, R. Zoos and Aquariums promote attitude change in visitors? A critical evaluation of the American Zoo and Aquarium study. Society and animals. v. 18, p. 126138. 2010.

MCPHEE, M.E.; CARLSTEAD, K. The importance of maintaining natural behaviors in captive mammals. University of Chicago Press. Chicago, p. 303313. 2010.

NETO, M.C.; KANDA, C.Z.; DORIA, E.C.; ZAMARRENHO, L.G.; GONÇALVES, F.H.P. Avaliação do bem-estar de um bugio (Alouatta caraya) cativo durante enriquecimento social e ambiental: indicadores comportamentais. Revista de etologia. v. 10, n. 1, p. 12-20. 2011.

OLIVEIRA, K.A.; CORONA, H.M.P. A percepção ambiental como ferramenta de propostas educativas e de políticas ambientais. Revista Científica ANAP Brasil. v. 1, n. 1, p. 53-72. jul. 2008.

OLIVEIRA, L.C.; LORRETO, D.; VIANA, L.R.; SILVA-JR, J.S.; FERNANDES G.W. Primate community of the tropical rain forests of Saracá-Taquera National Forest, Pará, Brazil. Brazilian Journal of Biology. v. 69, n. 4, p. 1091-1099. 2009.

PACHECO, G.F.E.; SAAD, F.M.O.B.; TREVIZAN, L. Aspectos éticos no uso de animais de produção em experimentação científica. Acta Veterinaria Brasilica. v. 6, n. 4, p. 260-266. 2012.

POTTER, V.R. Bioética ponte para o futuro (trad. Zanella, D. C.). São Paulo, Edições Loyola, 2016.

PREFEITURA MUNICIPAL DE CURITIBA. Secretaria municipal do meio ambiente. Zoológico e Passeio público. Disponível em: $<$ http://www.curitiba.pr.gov.br/conteudo/zoologico-e-p-publico-zoologico-epasseio-publico-smma/331> Acesso em: 16 out. 2017.

PREFEITURA MUNICIPAL DE CURITIBA. Secretaria municipal do meio ambiente. Casa do Acantonamento. Disponível em: $<$ http://www.curitiba.pr.gov.br/conteudo/casa-do-acantonamento/665> Acesso em: 16 out. 2017.

RAMOS, J.B. Bem-estar animal: a ciência de respeito dos animais. Instituto ecológico aqualune. Rio de Janeiro, v. 68, p. 4-5. 2006.

REGAN, T. Jaulas vazias, encarando o desafio dos direitos dos animais. Canoas, Lugano, 2006. 
RODRIGUES, L.S.F.; ALMEIDA, S.A.C.; RODRIGUES, A.F.S.F.; PREZOTO, F. Comportamento e distribuição de um grupo de macacos-prego (Cebus apella Linnaeus, 1758) mantido em cativeiro. CES Revista, Juiz de Fora, v. 24. 2010.

SADE, C. Visitor effects on zoo animals. The plymouthe student scientist. v. 6, n. 1, p. 423-433. 2013.

SILVA, E.V.C.; RUEDA, P.M.; RANGEL, J.M.R.; ZÚCCARI, C.E.S.N. Bemestar, ambiência e saúde animal. Revista Ciência animal brasileira. Campo Grande-MS. 2009.

SOUZA, J.F.J. Estresse em animais de zoológico. Tese (Especialização Latu Sensu em clínica médica e cirúrgica de animais selvagens) - Qualittas, Brasília-GO. 35f. 2010.

VAZ, L.L.; CARVALHO, M.P. Ecologia e comportamento de um grupo de macacos-pregos (Cebus spp.) (Primates: Cebidae) e frequência de contato com visitantes do parque Estadual Alberto Löfgren. Instituto Florestal Série Registros. São Paulo, n. 42, p. 121-125. jul. 2010.

YOUNG, R. J. Environmental enrichment for captive animals. Oxford: Blackwell Publishing, 2003. 